\title{
Perspective on Sexual Harassment of Women in Workplace
}

\section{Ehsan Rostamzadeh}

PhD of Law (Candidate), Faculty of Law, National University Malaysia, 43600, UKM Bangi, Selangor, Malaysia

*Corresponding Author; Email: ehsan_rostamzadeh@yahoo.com

\section{Reza Toranj Mehregan}

Judge of Justice and Lecturer at Judiciary Scientific Applied Training Center, Isfahan, Iran

\section{Doi:10.5901/mjss.2016.v7n2p69}

\section{Abstract}

This article explore the Iranian women's experience of sexual harassment at workplace, it effects on the harassed female workers and the coping strategies employed by them and the available laws that protect them from sexual harassment misconduct. This article focuses on sexual harassment in Iran which is relatively widespread. It is overwhelmingly directed at women, especially those in less-powerful position in the labour market. Analysis is also conducted on the Iran national legislation; its weakness and ignorance about harassment of working women at workplace and also the organization's fault in not having a good and serious policy and programs to protect and support women worker in work environments. Since people in order to economic need to be employment and they have to have relationship with individual and various group communities both man and woman at workplace. So workplace can be where for sexual harassment and also communication problems. According to labour law and human rights legislation, any statement and action has a gender massage, views or action that respondent does not accepted and become uncomfortable is considered sexual harassment. This is an analytical study.

Keywords: Sexual harassment, Workplace, Human rights, Labour law, Working Women.

\section{Introduction}

Women working in an organization are considered "taboo" in traditional Iranian society. In the modern society today, Iranian women are exposing to education and find opportunities to work in workplace. However women are seen to be in unequal position to men and they faces various types of discrimination at workplace, such as low salary, difficulty in getting promotion and experiences all types of harassment. Neglect of Iranian laws about this phenomenon, made it a serious and problematic for women during their life. Labour law as a main resource to protect all worker's rights, should be mention to all terms of workplace immune conditions both physical and psychological as vital issues because workplace has become home to many of workers and they spent more than half of their life there. Thus it is conducive working environment for both male and female employees. Islamic penal code also protects social security and public moral and ethics, must be more attention to social problems such as sexual harassment. Legal solution of sexual harassment has complicated for cursory glance and heedlessness of laws to it. This article analyzes and studies the working women's statute in Iran in recent decades. It also reviewed and discussed on sexual harassment at workplace issues among Iranian women workers and the reasons and factors that cause the increase and appearance of this of social phenomenon. Finally it examined the Iranian's domestic law and weaknesses of this law such as labour law and Islamic Penal Code Law and about the women's problems like sexual harassment at workplace. In this study, the data are of library type and the analytical method was used (Yaquin, 2007). The main objective is prevention of sexual harassment in workplace and to reach a better identification of differing's reasons of sexual harassment in workplace in Iran such as specific culture and custom, men's viewpoint about the working women, coupled with some traditional beliefs in the Iranian society.

\section{Background of Iranian Women's Employment}

Previously most Iranian women played the roles of mothers and wives that educate and prepare their children for healthy family life and pay less attention to their academic and intellectual activities as they were socialized to keep their house, give birth and raise children. They regard social activities and socializing is not beneficial and demeaning women. 
In Qajar Dynasty wealthy urban women were made detached from the society so that they only appeared in public when they went to bathroom or participated in religious meeting or attended female receptions. Poor and middle class women were forced to work in the farms, patches, textile workshops or small manual industries in order to make ends meet (Tajmohammadi, 2012). But, as the economic and social conditions of Iran changed and labour division becomes complicated, women assumed more important responsibilities such as joint employment in addition to their traditional responsibilities. Yet, Iranian women's employment had a very slow progress as slow economic developments were always associated with traditional perspectives backing the anti-women's opportunities in employment in Iran. The traditional perspectives have always been major impediments for working women (Kar, 2001).

Today, professions are broadly classified into traditional-underdeveloped and modern classes. Iranian women mostly work in traditional and non-formalized class. In the recent decades Iranian women's inclination towards education and technical and vocational specialties has drifted them to industrial and non-traditional education. However, according to studies conducted recently, $38.82 \%$ of Iranian women work in educational and cultural work sector and less than $5 \%$ of women work in technical, engineering and agricultural work sector. In other words, women are less focused on technical and engineering professions, and technical services. As a result, the society has recklessly dealt with drawing women into the labour market, especially in non-traditional and industrial professions, without preparing the environment and legislating sufficient supportive laws. In all, women face acute problems in their workplace. Iranian men and women have quite skeptical beliefs about women's involvement in employment (Madanipour, 2010).

\section{Men's Viewpoints of Previous Research Finding on Working Women}

As statistical study on Iranian men perception about women's employment and their role in individual and social lives, and also their viewpoints about the most suitable professions for women shows that men's beliefs about women's employment varies and this can cause major problems for working women. Based on the findings of the studies administered by Iranian Women Network in 2009, 24\% of Iranian men believed that women should only work at home, $28 \%$ believed that working brings vitality into women's lives, $24 \%$ of them believed that women should work to be independent and $24 \%$ held that working women failed to fulfill their responsibilities at home and they were against women's employment. Among the male whom agree to women's employment, $52 \%$ believed that cultural professions were the most suitable professions for women, $18 \%$ agree for women participation in artistic professions and $6 \%$ were for women in administrative professions (Madanipour, 2010).

As a result, more than a half of Iranian men hold that traditional, cultural and educational professions are the most suitable professions for women and they are against women's employment in non-traditional and industrial professions. In fact, this shows a kind of sexual discrimination against women and the contradictions among men's beliefs in terms of women's employment as acceptance of women's employment by imposing limitations that show disagreement with women's employment. Iranian men accept women's employment on one hand but limit it to specific professions and special conditions. Thus, stereotyping in women's work in

Workplace is practiced. For example women may choose to work only as teacher, nurses and tailors.

The finding on men's viewpoints on the positive or negative effects of women's employment and its role can be summed-up as follows:

i. $56 \%$ of men believe that women have no responsibility to support the family financially

ii. $34 \%$ believe that women should help to pay family expenses (preferably in traditional, cultural and educational classes).

iii. $10 \%$ of them believe that women's employment has no positive outcome (Madanipour, 2010).

The question is whether the male agree to women going to work in workplace and shall keep supporting women's employment after marriage? Mostly they do not support or agreeable to such wants by women.

As a conclusion we can say that although $76 \%$ of men agreed to women's working at workplaces, but about $52 \%$ of men only agree to women working in traditional professions. Men do not agree to allow women to work in nontraditional work and industries. They regard this as exposing women to public socializing and learning the traditional role as mother and wives in the house.

\section{Women's Viewpoints on Previous Research Finding of Working Women}

Similar analysis, conducted onto women about their views on working women. Unfortunately, there are many women whom are also against women working in the workplaces. Most Iranian women hold that traditional works are best left to women to conduct them. This shows that Iranian women experiences and practices in depth culture and traditional work 
socialization in their society. Their perception on this can be seen below:

i. $\quad 18 \%$ of women hold that women should work at home.

ii. $14 \%$ believed that having a profession bring vitality to women's lives.

iii. $\quad 64 \%$ hold that women should work to be independent and

iv. $4 \%$ believed that having a profession means failure to fulfill family duties (Madanipour, 2010).

So women can be categorized into two groups:

i. Women who said that having a job is a must; and

ii. Women who believe that having a profession said lead to independence and vitality (Madanipour, 2010).

The finding state that:

i. $96 \%$ of Iranian women are agreeable women's employment but, $56 \%$ of them hold that cultural professions are the best professions for women;

ii. $\quad 16 \%$ believe that artistic professions are good; and

iii. $10 \%$ are agreeable to administrative professions (Madanipour, 2010).

Studies on the women's viewpoints about the positive or negative effects and the role of women's employment in their lives show that:

i. $\quad 68 \%$ of the two groups believe that women's employment has positive effects

ii. $\quad 30 \%$ hold that it is partially good; and

iii. 2\% don't evaluate it as positive (Madanipour, 2010).

As a whole the survey conducted on men and women about working women shows that economic, social and cultural developments have to certain extent positively changed women and men viewpoints about working women. However, the perceptions differ strongly to women. Findings also shows that although Iranian women have taken measures towards participation in work and social activities they have not achieve independence in selection of the types of work want to participate. The studies show that $56 \%$ of Iranian women are agreeable with their traditional and social cultural needs and $2 \%$ of them are against women's employment altogether.

\section{The Concept of Sexual Harassment in Iranian Society}

Iranian society is regarded as traditional, closely knitted, religious society that promotes protection of their citizen. However occupational sexual harassment conducted onto women appear at workplace though not widely exposed to the public so that the victims' honour could be preserved.

Sexual harassment refers to degrading comments and sexual illusions or discriminating sexual elements that are annoyance for women and men that result in threat, exploitation, fear or hurt women or men and impact victim's performance and create risk to her or his work.

However, Iranian men and women regard harassment only took place when there are physical conducts (Doosti \& Sayadifar, 2007). Dr Ali Asghar Saeeidi, sociologist from Tehran University, considers that;

"Most of pointless action of men as a sexual harassment also he states that in European countries most of less important actions of men in workplace such as scrape of body, sexual pose offensive or sexual jokes or gags and even talking about some part of body are considered as sexual harassment, in contrast to Iranian imagination reacts such a thing with too much freak (Saeedi, 2006)."

It is significant that sexual harassment be viewed in a culture-bound concept, developed in line with the laws to regulate men and women relationship. For example in traditional society such as Iran, laughing at jokes of a sexual nature by an employer can be interpreted as a type of respect to him but it does not mean women welcome such kind of immoral verbal abuse or sexual. She is not supporting the employers' sexual jokes but may result in fear of termination of work. Some harassing conducts are not sexual in nature, but it happens just to exhibit men's ability to control women. In society where women are protected there are sufficient legal provisions that may prevent sexual harassment at the workplace and can reject any sexual offensive misconduct from the very start. So although in most countries definition of "sexual harassment" is the same but it has some difference in the applications and interpretation (Saeedi, 2006). Similarly to many third world countries can be integrated to mean any unwelcome verbal, visual, physiological conduct of a sexual or power nature that might, on reasonable grounds, be perceived by the victim, and affects her employment because of her sex. What is 'reasonable' in one society may be not reasonable in other society thus the definition of "sexual harassment" in Iran is vague as compared to the western (Saeedi, 2006). 


\section{Types of Harassment Experience by Women in Iran Workplace}

As mentioned earlier, women have participated conceptually in Iranian labour market, but unfortunately this empowerment have created problem in accommodating women's interest. The main root of this problem lies in the wrong traditional beliefs and male oriented system practiced in the Iranian society. This study identified specific kind of sexual harassment behavior that took place at work in Iran such as physical (touching) non-verbal and psychological. Sexual assault rarely happens in open spaces at Iranian workplace. Therefore mere touching accidentally or on purpose does not amount to assault, on the other hand. Western laws perceive touching as "assault". It's not significant if the happens one or repetitive. Touching in sexual harassment cases is considered an assault.

Thus, in order to better understand sexual harassment situation, first there is a need to categories the organization into two types, they are;

i. Private companies promote superior and inferior system and classification of ranking or hierarchical positions. Government's supervision on private companies on this matter is minimal. While work task, salaries, benefits, punishment and encouragements and others are provided by superior or manager of the organizations, thus they have absolute power to handle the other subordinate workers.

ii. Governmental organization that the superior and inferior systems govern the organizational operations. At this point, the government has more control and responsibility towards their employees as compare to the private companies. In these organizations, the administrator's power, to determine termination, appointment, salaries, benefits and others are subjected to various bureaucratic decision makers.

On the other hand, annoying and harassment of Iranian women at the workplace may be categorized in to two types that are;

i. First, harassment for sexual pleasure; that it's major purpose is to achieve sexual desires and favour from opposite gender, which that are similar to quid pro quo harassment concept. It means granting sexual favours to the harasser to gain a job, win promotion, or gain access to opportunities or other benefits. Failure to comply may lead to non-employment, denial of training and promotional opportunities, poor work assignment, or dismissal. Most of harassing behaviours in this group may be verbal (sexual comments on the from and quality of body parts and showing offensive sexual images or sexual jokes or gaps), visual (leering looks), physiological (immoral proposals) and in some cases physical annoyance (intentionally, apparently as accidentally touching the body) and the other offensive conducts such as, converging sexual inquiry in general sense or questions about the quality and types of sexual behaviour or individual's sexual orientation.

ii. The second type is offensive hostile environment harassment; that are provided by annoying and unbearable conditions for women by using male oriented force and power. This type of sexual harassment similarly to the first type, (harassment for sexual pleasure) creates uncomfortable situation for women. The main purpose is not to seek sexual desire; but certainly to humiliate women's gender or removes them from the workplaces and replaces their position. These behaviour range from humiliate, to disregard person's ability, to orders to label, create scandal, disgrace to someone life and other unpleasant behaviour or psychological pressures which usually conducted co-workers or and even male client against women managers and supervisors. This happened more in governmental work environments to compare to private companies. This is because of specific work circumstances that monitor government organization such as having special supervision and some ethical and moral policies that protect them from harassment for sexual pleasure invitation.

While in private companies, managers or employers are responsible of their "inferiors" employees' affairs. In such environment if women are at manager level or at least have superior positions, inferior men employee con not or rarely can harass or annoy their women head / managers, because they may be dismissed from their job or they are involve with other career problems, such as demoted. So sexual harassment problem are controlled to minimum level. On the other words, the chance of any forms of sexual harassment occurrence is less. But if men are superior to women, this does not solve the sexual harassment but it doubled. So the problem in such situation if a women does not comply with her employer then he tried to fire her or makes life difficult in her work environment and forcing her to leave her job or in return to his desires. These types of harassment for sexual desire and offensive work environment in private companies where male supervisor for female subordinate is indeed a bitter fact and lack of clear policy and concern supervisions in the organization are two major reasons for the expression of their problem. Also women managers and supervisors in governmental companies face obstacles in dealing with inferior men employees and clients who conducted sexual harassment on them and their women workers. This is because Iranian men due to their culture and tradition have difficulty accepting women who are in charge or managers in the organizations. Generally the existing traditional beliefs and male oriented governance in Iran is one of the major causes of this social struggle. 


\section{Women are Perpetrator or Victim?}

In sexual harassment scenario women can be perpetrator if she conduct sexual bribery, that are when women offers to fulfill her supervisor, manager or co-worker's desires to have sex in return for some gain, may it be monetary, position in the workplace and salaries. On the other hand women become the victim when she is forced into submission herself to the employers' sexual invitation and lust. However in most cases men were always perpetrator because men tend to be sexual when they are expected to work with women. They even want women to treat them similar as to how they were treated in their house such phenomenon is called sex-role carry-over into the workplace.

The increase of social developments and active participation of women in the society have created new work environment in Iran and the increased sexual harassment against women and have in consequence causes these social problems remain to be resolved. The duality of perspectives among Iranian women and men have created two different category of people, that are those who view that women are the cause of sexual harassment and others that women are victims of such.

In first category, people alleged women as causing sexual harassment. They believe many women become treat to men at the workplace have certain influence in sexual harassment problem. They argue that if women wear hijab and practice suitable behavior towards men they will not be harassed. This belief is widespread especially among the traditional people living in the small cities. This view may be rooted from culturally misperception on that impose perception. As a result, the society is more sensitive towards women behaviors and clothing as compared to men's behaviors. Thus on that basis women are said to initiate and cause sexual harassment at workplace due to such perceptions, issues on women dressing and their social relation in society have vital attention from the public to ensure society harmony. Thus men's involvements with sexual harassment against women at workplace were ignored and women free dressing are dominated monitor as moral and social deviation. In this way they were silenced in their workplaces the sexual harassment allegations may possibly be used against them. At this point it is not the perpetrators who were addressed but the victim who were further victimized.

Clothing is not the main reasons for sexual harassment practices at workplace. If unsuitable clothing is the cause of sexual harassment at work then the problem of sexual harassment shall be considered and limited to private companies' workplaces, because in governmental agencies Islamic ways of clothing and suitable policies are strictly monitored and controlled. However this is not wholly true because women working in governmental workplaces wear completely suitable Islamic clothing but still they become the targets of sexual harassments by male co-workers, either the superiors or inferiors. Ignoring, humiliation, defiance, mockery, showing offensive sexual movements and other hostile behaviors, are subtle forms of sexually related behavior that causes human sufferings and women internalized then in the governmental organizations. Therefore the existence of sexual harassment at workplace do not relate to women unsuitable clothing or misbehavior but only social wrong perception on to women. Men are seen free from misbehavior although they conduct sexual discrimination and harassment on to women. Unfortunately, even though it's the false traditional beliefs in the Iranian society, some women too have joint the men in promoting this wrong demeaning viewpoint.

The second category of people (mostly women) believes that women are victims of sexual harassment. They argue that the patriarchal culture, professional sovereignty and power of men are the causes of sexual harassment against women at workplaces. They also believe that from the very adolescence, boys discover that being a man means to enjoy some privileges. In fact the society impliedly authorizes the part of men bullying towards women. They also believes that cultural exploitation of women and patriarchy governing method in society and work environments lead men away from their human nature and lead them toward violence against women. In this respect, a sociologist Anthony Giddens defines 'sexual harassment as misuse of professional power or sovereignty to impose sexual demands' (Saboori, 2013).

\section{Sexual Harassment Increase and Its Existence in the Workplace}

Sexual harassment is on the increase and continually appears at workplace. These appear in various forms and there are many reasons for such to increase.

\subsection{Hidden Problem}

Sexual harassment is closely related to negative sexual relations that took place at workplace. It is unwanted, unwelcome and unacceptable nature to every day relationship at workplace. Hostile environment develops and for the victims they 
prefer to internalize this problem and try very hard to hide what happen at workplace. They fear that their co-worker will have wrong impression about her personality; she also fears that the manager may retaliate, or lessen her work benefits and opportunities for advancement in her career. Thus she prefers to hide the problem and suffer in silence.

\subsection{Power Relation and Competence}

The perpetrator and the victims have unequal because bargaining such as superior and the inferior, and employers and workers. This makes it easier for those in power to sexually harassed women and places them in a difficult position, whereas for co-workers they sexual harassed women to lesser ability to compete for better promotions, benefits and even to gain mere attention from the boss. The purpose is to create crisis at workplace and place women in demeaning situation. Many women and men really do not know what relation is appropriate and what characteristics it has. Victim usually does not realize that sexual harassment is conducted on them to enhance others power and lesser, her power to compete in the workplace.

\subsection{Hierarchical Structure System (HSS)}

Dr Saeedi mentioned that hierarchical structure system policy causes inequality in the organization. This is because there are those in inferior position and other in superior position. This creates a large flow of power relations at workplace and competition among the inferior (co-workers) become great and sexual harassment misconduct are used to workplace their competitors. Whereas these are the superior position used their power as provided by HSS to harass who are in weaker position (Saeedi, 2006).

In Iran, work environment HSS is applied strongly in the government organizations. This cause the workers to be disappointed when they are not able to report their sexual harassment problems the administrative procedures that needs paperwork, long winded processes provided in the regulations hindered women workers from talking any action. Finally their complaints are ignored and unheard after going through all these obstacles.

This is the disadvantages of practicing HSS. One more importance point is that, in most of governmental organization, there is a sector that is called Security Sector Organization.

The main task of this section is usually control the organization member's moral issue specially women, such as monitoring of women covering and veil and their behavior that should not be against of Islamic codes, and also focus on organization security issue. But unfortunately those harassment problems such as creating offensive work environment which abused women emotionally are not in their area to monitor.

\subsection{Women Vulnerable Status}

Vulnerable women, such as those having status like single mother, and young women have higher probability be harassed at workplace. Culture and society's views about them as tendering to be sexual objects or attracts men, influences how women are been portrayed at workplace. Their vulnerable status gives wrong perceptions that they invited sexual harassment. Women who have to go to work because of financial needs and to enhancing family economic, who head the family, are forced to be at workplace to provide maintenance and keep their family together. Sexual harassment conducted on them will force them to leave the workplace and cause them to seek for new job. As a result, women become easily unemployed and sometimes cause poverty to them.

\subsection{Weak Governance}

Monitoring of companies, especially the private and small organization is weak. In some companies, women harassment practices in job environment are never monitored. In government organization, due to specific regulation and monitoring on potential sexual harassment conducts lessen. However hostile work environment either explicitly or implicitly may happen more. Weakness of effective work policy implementation in all organization, governmental or private sectors causes sexual harassment being tolerated.

\subsection{Lack of Supervisors in the Organizations}

Iranian labour laws and regulation provide for the supervisors of female worker in the workplace. However most of the supervisors are men, thus sometimes they lack of interest and do not places importance on women's workers conduct 
onto them. They refuse to consult or complaint to their male supervisors because women are further harassed with nasty and verbal abuse. They were also accused of having moral problems, invited the harassment from men and male supervisors are not sensitive to women grievance at workplace.

\subsection{Absent of Legal Protection for Women}

The Iranian employment laws set provisions to support women, such as, in maternity leave, leave during breastfeeding, prohibition of harmful, dangerous, and difficult work for women, but there is no law to protect and support women in occupational security or to prevent from problems such as sexual harassment in work environments.

\subsection{Men Sense Women as Risks in the Workplace}

Men sense risks and hazard when women headed the organization because this made women superior as compared to some other men who work under her supervision. This wrong traditional belief makes it even difficult for women to work. In the administration, at home and the society, men ruled women. However, nowadays, the need to advance in industry, science and technology, and growth of women participations in the society lessen the power of Iranian men and cause them to sense these risks for allowing women to lead the organization. Thus this wrong traditional belief should change to the need for men and women working together to enhance the country, and society in every area of life. Men should learn to respect and tolerate women's existence and their contributions in the workplace, but not otherwise.

\subsection{Absence of Self Confidence in Women}

Unfortunately one of the causes for the increase in harassments against is because of the absence of self-confidence and independence in Iranian women. Some Iranian women do not like to accept high position in the organization responsibilities towards their employees for fear of the heavy duties. In most cases they prefer to be the inferior employee rather than senior manager. These cause men to be harassers in the workplace.

\section{Sexual Harassment Related Provisions in Iranian Laws}

Suitable regulations or laws and more importantly, correct enforcement of them in them in the society can prevent or at the least decrease some socially related problems. Certainly, the level of culture within the society and the rate of acceptance and implementation of these laws by the population would also play a pivotal role

\section{Incompetent and Weakness of the Laws}

In most cases, a majority of the women who were questioned about the reasons of sexual harassment that took place at home, the workplace or the society, had not only pointed out false traditional beliefs and the patriarchal culture confining women to the home, but had also insisted on the lack of supportive laws and the existence of unjust yet discriminatory laws against women. Iran's less attention and negligence on the women's moral and psychological well-being are apparent in almost all the rules of the country. In the Iranian domestic law, no reference is being made to the working women's dignity or to her existence as a human being who is working in the environment similar to men. The labour law should pay more attention to all workers including the women. Unfortunately even the Islamic Penal Code laws which refer to criminal offences against social security and morality in the public do not mention about this issue. Thus, it is necessary to study the existing Labour and the Islamic Penal Code of Iran and their impacts on the discrimination against women and the women's position at the workplace which has been ignored. This is clearly seen in the Iranian Labour law and its contents on women protection, as illustrated in the followings;

\subsection{Labour Law 1990}

The Iranian Labour law was approved on September 23 of 1989 by the Islamic parliament. And subsequently after many debates, reviews, reforms and some complementary issues, the law consisting of 203 article and 121 notes was sent to the Expediency Council for the final approval on November 29, 1990. The fourth part of the debate from third chapter of the labour law is about the working condition of women that have some valuable provisions on the working women, but unfortunately there is no article to safeguard the welfare of the working women with regards to sexual harassment at the workplace. 
Each year in Iran, the Labour and Social Affairs Department releases official statistics on reported occupational accident in the country. According to many independent researchers and officials, the statistics reflects largely on the unsafe conditions of the workplace. It does not however, highlight on the most glaring issue faced by the Iranian women workplace that women are often victims of sexual harassment at the workplace. It is obvious that neither the Ministry of Labour and Social Welfare nor the Labour law take into account of the plight faced by the female workers of Iran.

After scrutinizing various articles, it is obvious that the legal provisions do not mention about sexual harassment that are demeaning women at the workplace. It is thus safe to deduce that the legislators do not take into consideration the emotional well-being of a woman, including her sexual and emotional health safety as to be of any importance at the workplace when drafting the law.

It is also interesting to note that the Labour law which outlines on the safety and labour hygiene, there is no provision on the emotional safety sexual security at the workplace. The sexual safety of the women workers in the Iranian law is not considered as a labour hygiene, thus it is the failure on the part of the legislator to neglect on the women workers' physical and emotional well-being and more importantly on women's dignity. Moreover, sexual harassment issues and both is effects, either physical (stomach problem, headache, etc.) or emotional (anxiety, insomnia and stress, etc.) should be at least considered to be included into the safety and labour hygiene chapter of the labour law and it must be enforceable to all employers and at all times at the workplace.

\subsection{Islamic Penal Code Law 1991}

The Islamic Penal Law of Iran was approved by the Islamic Consultancy Parliament on July 30, 1991 and subsequently ratified by the High Expediency Council on November 28, 1991.

As mentioned earlier, sexual harassment of women at the workplace has become a phenomenon in the Iranian society due to law neglect and its failure to appear in any of the laws of Iran. In most cases, almost all of the laws in Iran merely mention sexual abuse as one which involves physical attacks; in other words the laws has failed to recognize any other kind of sexual abuses such as psychological, verbal or visual harassment in the home, on the streets and especially at the workplace which has resulted in making the conditions at the workplace intolerable for the working women at large. The Iranian legislators when formulating the Islamic Penal Code Islamic law have determined extensive provisions in supporting social security and public morals which unfortunately do not have in any of them even a mention of sexual harassment at the workplace. The related provisions are as follows:

'Article 637: Any man or women who are not married and who commits a crime against public morality, excluding adultery, should be sentenced to flogging ( 99 lashes). If one of them did not consent to the crime, then only the one who initiated the crime should be punished (Naserzadeh, 1996).'

This article can be divided into two parts. The first part of this section refers to a criminal act and is punishable due to an illicit relationship between men and women who are unmarried. It also states that the relationship may not be restricted to merely adultery, but may include any sexual and non-sexual conducts between the unmarried man and women. It is the second part of the article which attention is drawn to as it expresses that in the case where the sexual abuse is accompanied by rape and the only the delinquent would be sentenced. The provision allows for the victim to be proven innocent due to the existence of rape and coercion by harasser. In reality, the burden to prove of such act is the responsibility of victim, which could pose a big problem without any legal aids or provisions on the victim's part.

Briefly this section refers to some point which none of them because of reasons listed can support the women's rights in any cases involving sexual harassment:

i. To be a criminal and punishable, any illicit relationship (sexual or physical) between unmarried parties makes no reference to sexual harassment of women at the workplace specifically, but it is merely concerned on the illicit contact, thus it is out of the scope of this study.

ii. More attention is given to physical and sexual contacts. None what-so-ever is mentioned of any other forms of harassment such as the psychological, visual or verbal harassment of which their incidences are more frequent among men and women in the society.

iii. To punish the harasser alone is hinged on proving the victim innocent. (The ways of proving such are difficult and usually impossible. This would be explained later in this research.)

iv. The key point which clearly results in the victims not getting the relevant attention in court but given a rather weak and superficial investigation is due to this section which reads "legislator's silence in terms of consent under duress".

Sexual harassment is a crime in the public law and the criminals are dealt with according to the Islamic Penal Code unless the two parties have consented to the crime in which the case falls in the domain of private law. With regards to 
the severity in this field usually such agreement would not be considered in the private law as if the petitioner consents but the prosecutor shall follow up the case. In Islamic Penal Code the punishment of sexual relations is execution, stoning or 100 lashes that may be paid in cash. In compliance with article 637 of the Penal Code Law the punishment of sexual harassment if no adultery occurs in 99 lashes that may be punished. If sexual harassment results in rape, it may not be proven easily as there may not be any witnesses. Furthermore, rape is not easily proven by forensic medicine (Fathi, 2013).

According to article 637, when a woman succeeds in proving sexual harassment at the workplace, the criminal shall only be flogged to 99 lashes or pay a pecuniary punishment. However, the woman who is the victim will be further victimized, as show would lose her job at the workplace. The criminal, in all probability would usually be the employer or a superior to the woman/victim (Ghadeemi, 2005).

\section{Silent and Descend of Grievance}

According to inquires done by a group, attorney at law also an activist of women rights, emphasizes the problem of sexual harassment at the workplaces. Lawsuits in these cases are statistically very limited although verbal complaints are numerous. There are some reasons for such silence and scarcity of legal complaints:

i. Saving honour: As mentioned earlier speaking about sexual affairs is a taboo in the Iran society, thus they prefer to keep such problem to the storeroom. What more if it involve sexual crimes, especially that of a female petitioner. Unfortunately, in most incidences, when a petition is initiated, it is the woman who is accused wrongful by the society. Before even hearing the case, the female victim is already accused of encouraging such crime and unjustifiably the petitioner is turned into a defendant. This has been a belief that women are the causes of any sexual harassment at the workplace. In fact, the root of the problem is the traditional false belief of men by holding that women are the main causes of sexual harassment at the workplace.

ii. Financial problems and being afraid of losing job: Financial problems and being afraid of losing job the reasons that have lead the female victims to be forced to consent to the situation and even to sexual relations. In such conditions women are forced to accept the employer's demands and cannot object to such harassments at the workplace. They may even be punished for having illegal sexual relationship when filing a petition against further harassment. Thus, they are forced to remain silent and such at most of the times causes mental and psychological problems to women.

iii. Difficulty of Proving Claim: The third reason for the limited number of legal petitions is due the difficulty of proving the allegations. For proving such claims the victim is required to introduce a witness or submit a substantial proof. Usually sexual harassments at workplaces occur in private rooms away from eyewitnesses. The harasser rarely harasses the victim in public or in the presence of other colleagues and preferably harasses the victim at suitable times and places. Yet, it should be noted sexual harassment at the workplace is categorized into two categories:

a) Harassment with sexual purposes for satisfying sexual needs of men that is widespread in private companies and institutions; and

b) Sexual harassing done with the aim to humiliate superior female colleagues or ignore their abilities or to prove male sovereignty. In the latter situation women cannot file a legal petition as Iranian laws lack any provision in support of support of women against such men that make the workplace undesirable for women. Therefore, in none of the harassment against women at workplaces cases women can prove their claims as there no legal provisions against such misconducts and the society does not support female victims. In such conditions women are forced to accept the conditions or keep silent or quit their job.

iv. Legal Bodies are Male Dominated: The most important impediment on the way to adjudication in Iran is the male dominance over legal bodies (administrators) from police offices to prosecutor's offices to courts of law. A woman hardly can promote her problems in such places. In addition, formalities are complex and lengthy. Worst of all, women are forced to tolerate the crushing significant looks from legal authorities given to them. Regarding the false tradition that a women's presence in the court of justice or police department means the criminal is due to her. Undoubtedly, due to such problems all rooted in false traditions and the patriarchal culture, thus how can women and girls defend their rights despite all the impediments preventing them from proving their claims? Thus, the claim that when reality cannot be changed, but mentality will be changed is true and the innocent women can do nothing but to change their mentalities or fight the reality that in turn results in failure in proving their claims, being convicted for ethical wrongs and finally expulsion from work and financial problems. 


\section{Ways of Prove}

In Iran if a victim of sexual harassment, despite all the impediments, insists on pursuit of her petition, she is bound to pass through difficult stages and in most cases she shall fail. There are three ways to prove such crime:

i. Criminal's confession: it means the man who harasses a women admits to his act, which is possible by the expert help such as the investigators, but, unfortunately, only in severe cases do serous investigation takes place. Sexual harassment is not considered a serious case as opposed to some physical harassment and rape. According to law almost all forms of sexual harassment, such as psychological and moral harassing, are dealt with superficially and not important.

ii. Eye-witness: Usually, sexual harassment happens in such places where no witness is present. But woman needs witness for proving this crime.

iii. Substantial proofs: Such as recorded voice, film or photos which typically are not so effective, because firstly a harasser usually harasses implicitly his victim, so availability of such proofs are usually almost absent. Also in such action, the repercussion for the victimized women can be safely predicted: it may cause many problems for the victim, including the dismissal from work. Indeed the laws are insufficient regarding this becomes sexual harassment occurs in enclosed and lonely places and the victims cannot prove their claims. If the laws are to be changed, then judges can use investigation techniques to get the truth (Arzani, 2007).

\section{Conclusion}

Women's participation in society and the workplace, as in any other countries are increasing. However, the problem of sexual harassment taking place at the workplace in Iran cannot be denied. Although this phenomenon exists in other parts of the world but the kind of behavioral harassment, types and causes of sexual harassment in Iran are distinctively different from those occurring in the other parts of the globe. This is true because of some reasons such as specific culture and custom, men's viewpoint about the working women, coupled with some traditional beliefs in the Iranian society. The male dominated workforce cannot be ruled out as one of the other reasons for such distinction from the other countries. What may be considered as sexual harassment in Iran may be deemed irrelevant in some Western or Eastern countries, or vice versa. In fact the concept of sexual harassment is different based on various culture and custom across the civilization. It is also noted that the causes of the harassing behavior towards women in the job environment are divers.

Generally there are two types of sexual harassment, one is sexual coercion and the other is sexual annoyance and most of the harassing behaviors in the Iranian job environment are visual and psychological. They were almost always taking place in governmental organization because of specific discipline, and the danger of sexual annoyance is more that sexual coercion. This study recognized the wrong traditional beliefs and lack of supportive for the women workers and the inherent absence of an effective policy in organization as the most importance causes of sexual harassment. Neglect to the problems and the frustrations of the women and the existence of discriminative laws against them and particularly due to the culture and its people's misconstrued viewpoint that the women's poor covering of herself and her attitude as essentially the causes of sexual harassment. Accordingly, harassments faced by women at the job environment cannot be justifiably discussed in all workplaces even where suitable covering is governed as there are other types of sexual harassment which are not related to sexual behavior sexual nature, but is related to men's personality perspective about women, and then cannot accept and believe the ability of women. So the occurrence of women at workplace are blamed for the cause of a rising sexual harassment causes due to their misbehavior may be true in some remote cases, but it is largely not true in most of the cases in that country.

It is undeniable that the sexuality of women develops conditions for increasing incidence of sexual harassment at the workplace. On the other hand, it is considered a shame and taboo in the Iranian society that this problem is the cause to such acts, thus in most cases, they are made unknown to the public. The most essence of the problem which makes it a silent scourge is that women were threatened, insulted or even raped by the employers. However, they cannot express their problem due to the incapability of the existing laws. The needs for the labour law to protect women on the women's moral well-being are being ignored. The provision for a safe and healthy condition in workplace, a basis of women's workers' rights has been trampled unfairly. Difficult and somewhat impossible to prove and no means for legal protection are the other reasons of increasing occurrence of sexual harassment. According to article 637 of the Iranian Islamic Penal code Law, if a victim of sexual harassment can prove her claim, the criminal shall be flogged to 99 lashes or face a pecuniary punishment. The criminal shall not receive any serious punishment but the victim shall be forced to accusations if she is unable to prove her claim and would eventually losses her job. Thus, in most cases when sexual harassment has 
occurred it is the victim (women) who is held to guilty as well as receiving no support. So this Article is insufficient in protecting women from sexual harassment because of the way that such legal needs are so difficult to prove.

\section{References}

Arzani, Z. (2007). Sexual Harassment A Gloomy Reality. Etemad Journal, 7:1-18.

Doosti, A., \& Sayadifar, S. (2007). Sexual Harassment in Workplace. Etemad Journal 8:1-32.

Eghlima, M. (2005). Sexual against Women. Hambastegi Journal, 28:1-21.

Fathi, M. (2013). Women and the new Islamic Penal Code. Mehrkhaneh Journal, 67: 24-45.

Ghadeemi, A. (2005). Sexual Harassment of Women at Workplace Women are Perpetrator or Victim. Women Journal, 4:8-27.

Kar, M. (2001). The Political Participation of Women: Barriers and Facilities, $4^{\text {th }}$ Edition, Rooshangaran Publication, Tehran, Iran.

Madanipour, N. (2010). Occupational, Effective, Causes, Barriers and Viewpoints. Payam Zan, 15(5), Retrieved from http://daftarmags.ir/ Journal/Text/PayamZan/Article/index.aspx? Article Number=7084/on (November 16, 2010).

Mansour, J. (2013). Labour Law, $6^{\text {th }}$ Edition, Doran Publication, Tehran, Iran.

Naserzadeh, H. (1996). Islamic Penal Code, $5^{\text {th }}$ Edition, Khorshid Publication, Tehran, Iran.

Saboori, M. (2013). Sociologist. $1^{\text {th }}$ Edition, Nei Publication, Tehran, Iran.

Saeedi. A. (2006). Sexual Harassment and Society. Etemad Journal, 6:5-17.

Tajmohammadi, P. (2009). Reviews Sexual Harassment for Women at Workplace. Nasir Boshehr Journal, 31: 55-73.

Yaqin, A. (2007). Legal Research and Writing, 1th Edition, Lexis Nexis Publications, Kuala Lumpur, Malaysia. 